\title{
Hormonal treatment in advanced non-small cell lung cancer: fact or fiction?
}

\author{
J.F. Vansteenkiste*, J.P. Simons**, E.F. Wouters**, M.G. Demedts*
}

\begin{abstract}
Hormonal treatment in advanced non-small cell lung cancer: fact or fiction? J.F. Vansteenkiste, J.P. Simons, E.F. Wouters, M.G. Demedts. CERS Journals Ltd 1996. ABSTRACT: In patients with advanced non-small cell lung cancer, cachexia is an important cause of morbidity and mortality. The pathogenic mechanism of this finding, usually referred to as "cancer anorexia and cachexia syndrome" (CACS), is complex and far from completely understood, but a disturbed equilibrium between possible food intake and metabolic needs seems to be fundamental. The literature data on the treatment options in advanced non-small cell lung cancer (NSCLC) with cachexia are reviewed.

Based on the clinical studies on cancer cachexia, some recommendations for the therapeutic approach of this disorder in patients with advanced NSCLC can be given. Metoclopramide is easily administered, can alleviate gastric disturbances, but probably does not correct the catabolic spiral of CACS. There are not enough data to advise the use of parenteral nutritional support, hydrazine, cyproheptadine, tetrahydrocannabinol or nandrolone decanoate. Corticosteroids are useful in additional analgesia and fast palliation of very weak and debilitated patients in the final episode of their disease. Recent data in non-small cell lung cancer patients are in favour of the use of high-dose progestagens to improve both appetite and weight. Eur Respir J., 1996, 9, 1707-1712.
\end{abstract}

\begin{abstract}
*Respiratory Tumours Unit, Dept of Pulmonology, University Hospital Gasthuisberg, Catholic University, Belgium. **Dept of Pulmonology, University Hospital Maastricht, Maastricht, The Netherlands
\end{abstract}

Correspondence: J.F. Vansteenkiste Dept of Pulmonology

University Hospital Gasthuisberg Catholic University B-3000 Leuven

Belgium.

Keywords:

Cancer anorexia and cachexia syndrome lung neoplasms palliative treatment progestagens

Received: February 231996

Accepted after publication March 251996
Metastatic non-small cell lung cancer (NSCLC) has a very poor prognosis, with a median survival of 3-5 months in nonselected patient groups, e.g. local cancer registries [1]. Cisplatinum-based combination chemotherapy can give a small but significant survival benefit $[2,3]$. Further multicentre studies with new cytotoxic agents in NSCLC are needed to improve the current survival results. In the mean time, clinicians are investigating the role of chemotherapy in symptom control and improvement of quality of life $[4,5]$.

Beside this, other palliative treatment modalities have been studied in controlled clinical trials. One of the characteristics of patients with advanced NSCLC is the development of progressive weight loss and cachexia. This detrimental evolution is usually referred to as "cancer anorexia and cachexia syndrome" (CACS), in accordance with similar clinical pictures in a range of other malignant processes.

After a short statement on occurrence, pathogenesis and clinical aspects, the different treatment options in NSCLC with so-called CACS are reviewed.

\section{Occurrence of CACS}

CACS is an important cause of morbidity and mortality in cancer patients in general [6]. At least half have socalled clinical CACS, a complex abnormal biochemical state, as a result of anorexia, inadequate food intake and inadequate food metabolism, and leading to progressive weight loss and tissue-wasting, poor performance status and, finally, death [7].

There is considerable variation in the occurrence of CACS according to the type of tumour [8]. Major weight loss is rare in breast cancer, sarcoma and some lymphomas. Impressive weight loss can be found in patients with gastrointestinal tumours, especially gastric carcinoma, where food intake is obviously disturbed.

Patients with severe CACS have poorer treatment response and survival [9]. Weight loss is also, besides tumour stage and performance status, a major prognostic factor in NSCLC [10]. Finally, a relationship between weight loss and poor survival has been demonstrated in NSCLC [11].

\section{Pathogenesis of CACS}

The pathogenic mechanism of CACS is complex and far from completely understood. An overview of contributing factors is given in table 1 . More details on animal models, biochemical and metabolic studies can be found in the recent review by NELSON [12]. The fundamental aspect of weight loss is a disturbed balance between food intake and increased metabolic needs. In NSCLC, in particular, weight loss is related to hypermetabolism [13], resulting in a negative energy balance [14]. The higher metabolic rate could be partially explained by the presence of an inflammatory state [15]. Other reported factors probably inducing an increase in metabolic 
Table 1. - Aetiological factors in CACS

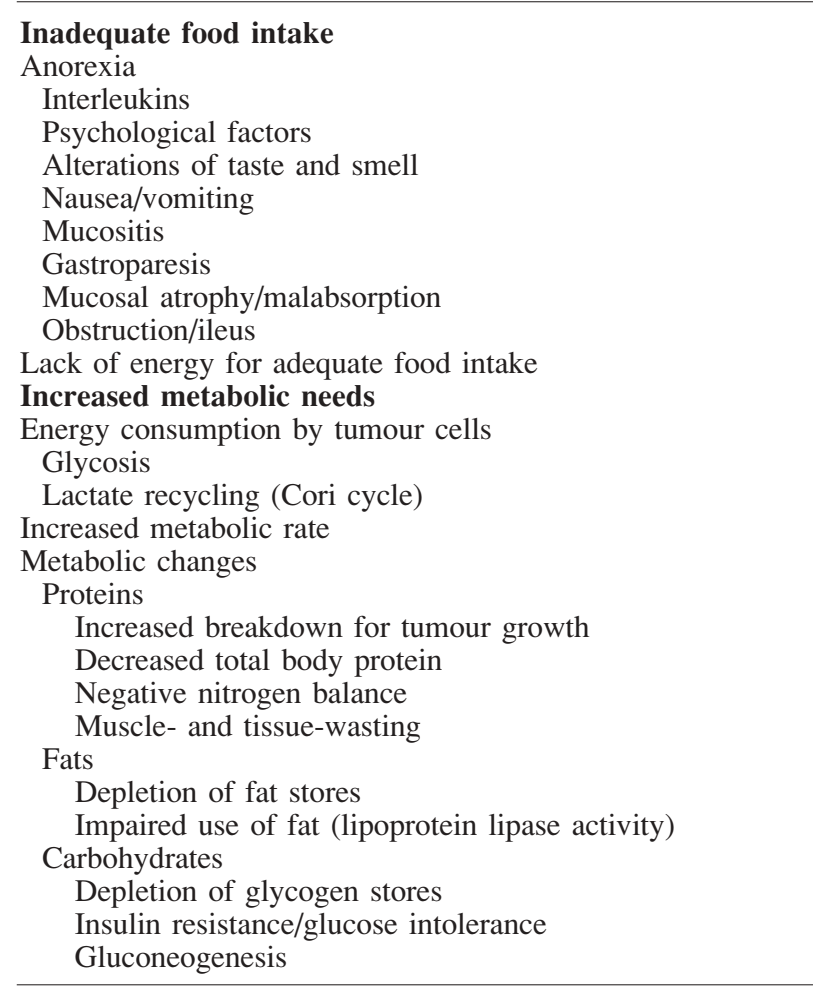

CACS: cancer anorexia and cachexia syndrome.

needs are tumour growth, with inefficient, and thus very consuming, mechanisms and numerous tumour-induced metabolic disturbances, all causing a less efficient use of nutrient intake. In contrast to starvation, where energy rich fat is used as primary fuel, in patients with CACS a defective fat metabolism (less lipoprotein lipase activity, excess-ive mobilization of triglycerides) is reported. In this sett-ing, glycogen and proteins, in particular, may be used as energy source [16], which results in muscleand tissue-wasting, and clinically in the initiation of the so-called "cachectic spiral".

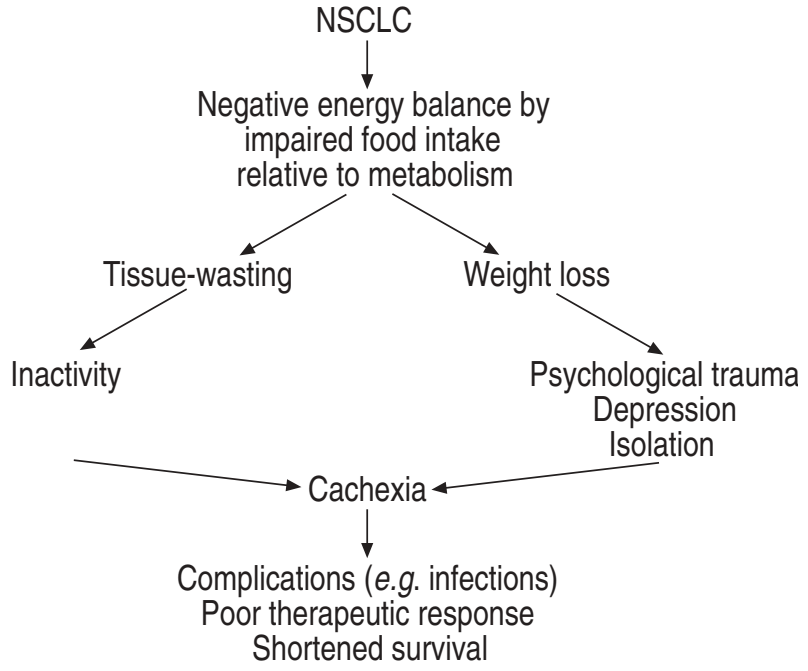

Fig. 1. - Clinical picture of cancer cachexia. NSCLC: non-small cell lung cancer.

\section{Clinical picture}

The pathogenic mechanisms of CACS bring patients with advanced NSCLC into the so-called "cachectic circle" or "cachectic spiral", schematically depicted in figure 1 . Food intake is inadequate to counterbalance the increased metabolic needs, and this negative energy balance will lead to tissue-wasting, clinically manifested by loss of weight. The perception of ongoing weight loss can cause psychological trauma, depression and isolation, which in their turn can promote anorexia and diminished food intake. Tissue- and muscle-wasting induce low performance status and inactivity. The end result is cachexia, higher susceptibility to complications such as infections, less optimal response to or increased toxicity of potential anti-cancer treatments [8], and shortened survival $[8,17]$.

\section{Treatment}

\section{Nutritional support}

Clinical and biochemical features suggest that nutritional support is needed in the presence of weight loss of more than $10 \%$ of the initial body weight, or in a situation where an aggressive anticancer treatment can be foreseen [18].

Where parenteral nutrition can be useful in patients scheduled for gastrointestinal cancer surgery, in which mechanical factors impede adequate food intake [19], and in patients treated during short intervals with highly effective chemotherapy, the indication for parenteral nutritional support is questionable in NSCLC [11, 20-22]. In as far as energy expenditure in these often hypermetabolic patients cannot be balanced by normal food intake, nutritional supplementation, particularly by enteral solutions, has to be considered. Taking into account the possible complications (catheter infection, pneumothorax) and the high cost (prolonged hospital stay), parenteral nutritional support in CACS can be considered as "oncologically illogical" [23].

\section{Pharmacological agents}

Besides the use of specific agents, one must remember to give attention and proper treatment to other aspects contributing to the anorexia, such as pain, mucositis, constipation, nausea and depression.

Several placebo-controlled studies in cancer cachexia show that placebo effects can substantially influence the results. Small, uncontrolled clinical studies must, thus, be interpreted with a large amount of caution, and are only mentioned in this review in those instances where no controlled data are available.

In view of the different pathogenic mechanisms contributing to tissue-wasting in cancer patients, in many studies data interpretation is hampered by the lack of specification or stratification for type of tumour.

Nonhormonal agents (table 2). Cyproheptadine is an antihistamine compound with antiserotonergic action, which 
Table 2. - Data on the studies with various pharmacological agents in CACS

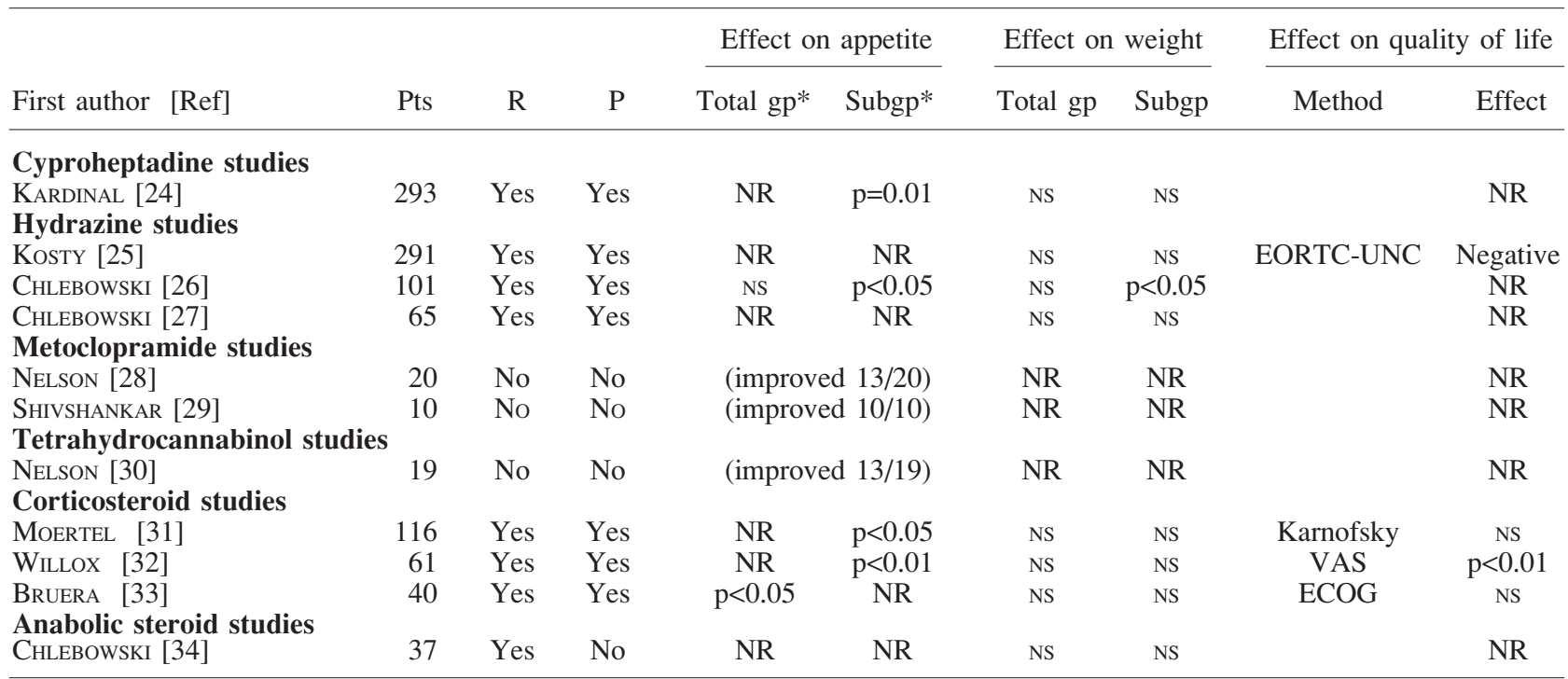

*: see text for explanation of these groups (gp). CACS: cancer anorexia and cachexia syndrome; Pts: patients; R: randomized; P: placebo-controlled; NR: not reported; NS: not significant at the $\mathrm{p}=0.05$ level; EORTC-UNC: questionnaire from the European Organisation for Research and Treatment of Cancer/University of North-Carolina; VAS: visual analogue scale; ECOG: performance status score of the Eastern Co-operative Oncology Group.

is well-known for its appetite stimulation. KARDINAL et al. [24] randomized 293 patients with advanced malignancies and weight loss of at least $2.2 \mathrm{~kg}$ between placebo and treatment with cyproheptadine, $8 \mathrm{mg}$ t.i.d. Improvement in appetite was noted in $55 \%$ of treated patients versus $36 \%$ in the placebo group $(\mathrm{p}=0.01)$. There was no influence on weight loss. Dizziness and sedation were disturbing side-effects.

Hydrazine sulphate was a promising therapeutic possibility. This substance is known to block a gluconeogenetic enzyme of the Cori cycle, a postulated inefficiently hyperactive metabolic pathway in cancer. A controlled trial by CHLEBOWSKI and co-workers [26] on 101 patients with a weight loss of at least $10 \%$ of initial body weight showed that $63 \%$ of the patients treated with hydrazine sulphate, $60 \mathrm{mg}$ t.i.d., had improved appetite versus $25 \%$ of placebo group $(\mathrm{p}<0.05) ; 83 \%$ of the treated group maintained their weight or gained $2.5 \mathrm{~kg}$ versus $53 \%$ in the placebo group $(\mathrm{p}<0.05)$. The striking results with placebo were attributed to intensive dietary counselling. In another study by CHLEBOwSKI and co-workers [27], 65 patients with advanced NSCLC treated with cisplatinbased chemotherapy randomly received either hydrazine sulphate $60 \mathrm{mg}$, t.i.d., or placebo. Dietary counselling was well-balanced between the two groups. Caloric intake and albumin maintenance were better in the hydrazine sulphate group, there were no significant differences in evolution of weight. There was a trend to better survival in the patients treated with hydrazine sulphate, especially if they had a good initial performance status. This was not confirmed in a more recent controlled, large scale study by Kosty et al. [25]. They randomized 291 goodperformance patients with advanced NSCLC between standard cisplatin-based chemotherapy or the same plus hydrazine, $60 \mathrm{mg}$ t.i.d., There was no difference in appetite, evolution of weight, quality of life or survival between the groups.
Metoclopramide can improve gastric function in patients with gastroparesis, which is often present in patients with advanced cancer [28]. Data on this compound are limited and consist only of small, noncontrolled series [29, 35]. They show improvement in appetite in some patients with advanced cancer and early satiety treated with metoclopramide, $10 \mathrm{mg}$ q.i.d., There was no effect on weight.

Appetite stimulation was noted when tetrahydrocannabinol was used in the prevention of nausea and vomiting induced by chemotherapy. Limited uncontrolled data also suggest a beneficial effect on appetite in CACS [30].

Adrenal steroids (table 2). Corticosteroids such as dexamethasone or methylprednisolone are often used in advanced cancer patients not eligible for curative treatment. In an early study, the only noteworthy difference was a higher incidence of peptic ulcers on autopsy in the patients treated with corticosteroids [36]. In the doubleblind, controlled study by MoERTEL et al. [31], dexamethasone, $6 \mathrm{mg} \cdot \mathrm{day}^{-1}$, or placebo was given to patients with far-advanced gastrointestinal adenocarcinoma [33]. Fifty five percent of treated patients experienced better appetite versus $26 \%$ in the placebo group $(\mathrm{p}<0.05)$. There was no beneficial effect on weight. Two studies used a randomized, double-blind, crossover design [32, 33]. The study by BRUERA and co-workers [33] showed an improvement in appetite in the total group: the visual analogue scale for appetite (0-100) improved from $26 \pm 10$ to $40 \pm 15$ $(\mathrm{p}<0.05)$. No advantage in weight could be seen. Interestingly, the visual analogue scale for pain decreased from $58 \pm 15$ to $37 \pm 14(\mathrm{p}<0.01)$, showing a supplementary effect of corticosteroids in (co-)analgesia. None of these studies demonstrated any advantage in performance status measured by Karnofsky or Eastern Co-operative Oncology Group (ECOG) scores. On the contrary, one could expect the opposite, when considering the multiple disadvantages of long-term corticosteroids: peptic ulcers, disturbed 
Table 3. - Data on the studies with high-dose progestagens in CACS

\begin{tabular}{|c|c|c|c|c|c|c|c|c|c|c|c|}
\hline \multirow[b]{2}{*}{ First author [Ref] } & \multirow[b]{2}{*}{ Pts } & \multirow[b]{2}{*}{$\mathrm{R}$} & \multirow[b]{2}{*}{$\mathrm{P}$} & \multirow{2}{*}{$\begin{array}{l}\text { Daily dose* } \\
\text { mg }\end{array}$} & \multirow{2}{*}{$\begin{array}{l}\text { Duration } \\
\text { weeks }\end{array}$} & \multicolumn{2}{|c|}{ Effect on appetite } & \multicolumn{2}{|c|}{ Effect on weight } & \multicolumn{2}{|c|}{ Effect on quality of life } \\
\hline & & & & & & Total $\mathrm{gp}^{\#}$ & Subgp\# & Total $\mathrm{gp}^{\#}$ & Subgp & Method & Effect \\
\hline \multicolumn{12}{|l|}{ MA studies } \\
\hline Feliu [38] & 150 & Yes & Yes & 240 & 8 & NS & $\mathrm{p}=0.001$ & NS & $\mathrm{p}=0.01$ & Karnofsky & NS \\
\hline LOPRINZI [39] & 133 & Yes & Yes & 800 & $7^{\dagger}$ & NS & $\mathrm{p}=0.003$ & NS & $\mathrm{p}=0.003$ & & NR \\
\hline TCHEKMEDYIAN [40] & 89 & Yes & Yes & 1600 & 4 & NS & $p=0.02$ & NS & NS & VAS & NS \\
\hline SCHMOLL [41] & 55 & Yes & Yes & $480-960$ & $4-8$ & NS & NS & NS & NS & & NR \\
\hline BRUERA [42] & 40 & Yes & Yes & 480 & 1 & $\mathrm{p}=0.02$ & NR & $\mathrm{p}=0.03$ & NR & Questionnaire & NS \\
\hline \multicolumn{12}{|l|}{ MPA } \\
\hline SIMONS [43] & 206 & Yes & Yes & 1000 & 12 & $\mathrm{p}=0.01$ & NR & $\mathrm{p}=0.04$ & NR & EORTC & NS \\
\hline NIIRANEN [44] & 89 & Yes & No & $180^{\$}$ & 24 & NS & $\mathrm{p}=0.02$ & NS & $\mathrm{p}=0.03$ & & NR \\
\hline DOWNER [45] & 60 & Yes & Yes & 300 & 6 & $(\mathrm{p}<0.01)^{\ddagger}$ & NR & NS & NS & Karnofsky & NS \\
\hline
\end{tabular}

*: a daily dose of $160 \mathrm{mg}$ megestrol acetate is equivalent to 1,000 mg MPA; \#: see text for explanation of these groups; $†$ : median duration of follow-up; \$: average daily dose (calculated from weekly i.m. dose); $¥$ : significant difference between appetite before and after treatment within the MPA group. MA: megestrol acetate; MPA: medroxyprogesterone acetate. For further definitions see legend to table 2 .

glucose metabolism, bone loss, fluid retention and proximal myopathy, with decreased muscle strength.

Anabolic steroids, such as nandrolone decanoate, improve the nitrogen balance and could help to preserve total body protein in cancer patients [37]. In a randomized study with only 37 inoperable NSCLC patients, nandrolone decanoate, $200 \mathrm{mg} \cdot \mathrm{week}^{-1} \mathrm{i} . \mathrm{m}$. for 4 weeks, was compared to no additional therapy [34]. Appetite was not scored. There was a nonsignificant trend towards less weight loss in the treated group. Solid conclusions are hampered by the small number and the short follow-up. However, longer use of this high dose would probably result in important side-effects.

Progestagens (table 3). Progestagens have been used extensively in the treatment of hormone sensitive breast cancer [46]. In early studies with high dose, one of the remarkable findings was the improvement in appetite and weight in patients with non-hormone sensitive or nonresponding breast tumours. Further studies in other solid tumours were initiated.

Megestrol acetate (MA) was studied in three NorthAmerican and two European randomized, controlled trials. Patients with incurable, non-hormone sensitive cancer and varying weight loss (usually $5-10 \%$ of initial body weight) were included. One study was too small to draw any meaningful conclusions [41]. Of the four remaining MA studies, BRUERA and co-workers [42], using a cross-over design with a treatment duration of 1 week, found a statistically significant beneficial effect for appetite (scored on a visual analogue scale from 0 to 100 , average improvement of +15 points in the treated group versus average loss of -12 points in the placebo group; $\mathrm{p}=0.02$ ), caloric intake, weight (average gain $+0.2 \mathrm{~kg}$ versus average loss $-0.8 \mathrm{~kg}, \mathrm{p}=0.03$ ), triceps skinfold thickness and subjective energy level. The clinical significance of these findings is, however, unclear given the very short follow-up. The other three studies [38-40] showed a significant beneficial effect of MA on appetite. Two of these studies also found that the subgroup of patients with weight gain was significantly larger in the MA arm than in the placebo arm: LoPRINZI et al. [39] found a favourable effect on weight (defined as an increase of at least $15 \mathrm{lb}$ ) in $16 \%$ of the MA-treated patients versus
$2 \%$ in the placebo-group; FELIU et al. [38] observed a weight gain of at least $2 \mathrm{~kg}$ in $32 \%$ of the MA-treated patients versus $8 \%$ in the placebo group. Quality-of-life was looked at in three studies, no significant beneficial influence of MA was documented.

Medroxyprogesterone acetate (MPA) was used in three randomized European studies. In the British study by DOWNER et al. [45], 60 patients with advanced malignancy, usually lung cancer, were randomized between MPA, $100 \mathrm{mg}$ t.i.d., or placebo. The visual analogue scores for appetite $(0-100)$ of the MPA-treated patients significantly improved during the study interval, data on comparison with the placebo-treated patients were not mentioned. No effect on weight or Karnofsky performance status was shown. Unfortunately, this study suffered from a lack of power (as a result of the relatively small number of 60 randomized patients, in combination with a drop-out rate of over $50 \%$ at the end of the 6 week treatment period), impeding the interpretation of its results.

A Finnish study by NIIRANEN et al. [44] randomized elderly lung cancer patients between a treatment with either chemotherapy or chemotherapy and MPA i.m. for 6 months. This study was not placebo-controlled. It was revealed that a subgroup of $37 \%$ experienced better appetite in the MPA-treated group versus $14 \%$ in the others $(\mathrm{p}=0.02)$; corresponding figures for weight gain were 27 versus $7 \%(\mathrm{p}=0.03)$.

In the Dutch-Belgian trial by Simons et al. [43], 206 patients with advanced, non-hormone sensitive cancer, predominantly lung cancer, were randomized between MPA, $500 \mathrm{mg}$ b.i.d., or placebo. Concomitant chemotherapy was allowed, but used in only $12 \%$ of patients in both study groups. Primary end-points were appetite (visual analogue scale $0-10$ ), weight and quality of life (European Organization for Research and Treatment of CancerQuality of Life Questionnaire-C30 (EORTC-QLQ-C30) [47]). Both appetite and weight were significantly better in the entire group of MPA-patients versus those with placebo. After 12 weeks, appetite showed a +0.8 increase for MPA and -0.6 decrease for placebo $(\mathrm{p}=0.01)$. Data for weight were $+0.6 \mathrm{~kg}$ for MPA and $-1.4 \mathrm{~kg}$ for placebo $(\mathrm{p}=0.04)$. Patients with oedema were excluded in the weight analysis in order to guarantee the solidity. Improvement in Karnofsky performance status approached 
significance after 6 weeks $(\mathrm{p}=0.07)$. No benefit in quality of life could be demonstrated by the EORTC-questionnaire. As in other studies, the possible side-effects of MPA (especially thrombosis, diabetes, fluid retention and hypertension) were mild; only fluid retention was somewhat more pronounced in the MPA group when compared with placebo.

Simons and co-workers [48] also analysed energy intake and body composition in a subgroup of patients participating in the multicentre trial. Compared to the placebo group, the MPA-treated patients showed a significant increase in energy intake of more than $400 \mathrm{kcal} \cdot \mathrm{day}^{-1}$. Body composition analysis revealed that the induced weight changes (mean difference in weight change between the two groups of $3.0 \mathrm{~kg}$ in favour of MPA) could be attributed almost completely to changes in fat mass, fluid retention being of negligible importance.

\section{Conclusion}

Based on the clinical studies on cancer cachexia, some recommendations for the therapeutic approach of this disorder in patients with advanced NSCLC can be given. Metoclopramide is easily administered and has a low cost. It can alleviate gastric disturbances, but it is unlikely that this drug would correct the catabolic spiral of CACS. Further controlled data are needed to determine its role precisely.

There are not enough data to advise the use of parenteral nutritional support, hydrazine, cyproheptadine, tetrahydrocannabinol or nandrolone decanoate.

Corticosteroids are useful in cases where additional analgesia is required, and for fast palliation of very weak and debilitated patients in the final episode of their disease. In other instances, they should be avoided for their multiple disadvantages.

In non-small cell lung cancer patients data of reported studies are in favour of the use of high-dose progestagens to improve both appetite and weight. The cost of this treatment, however, warrants further confirmatory evidence, especially on quality of life issues. In the meanwhile, we think that the current data allow us to suggest that palliative hormonal treatment of non-small cell lung cancer patients with cachexia is becoming more than fiction.

\section{References}

1. Vansteenkiste J, Weyler J, Thibaut A, et al. A hospital-based lung cancer registry in Flanders/Belgium: recent data and survival analysis on 2,709 patients. Lung Cancer 1994; 11 (Suppl.): 53 (Abstract).

2. Rapp E, Pater J, Willan A, et al. Chemotherapy can prolong survival in patients with advanced non-small cell lung cancer: report of a Canadian multicenter randomized trial. J Clin Oncol 1988; 6: 633-641.

3. Souquet P, Chauvin F, Boissel S, et al. Polychemotherapy in advanced non-small cell lung cancer: a meta-analysis. Lancet 1993: 342: 19-21.

4. Jaakkimainen L, Goodwin PJ, Pater JL, et al. Counting the costs of chemotherapy in National Cancer Institute of Canada: randomized trial in non-small cell lung cancer. J Clin Oncol 1990; 8: 1301-1309.
5. Ellis PA, Smith IE, Hardy JR, et al. Symptom relief with MVP (mitomycin C, vinblastine and cisplatin) chemotherapy in advanced non-small cell lung cancer. $\mathrm{Br} J$ Cancer 1995; 71: 366-370.

6. Theologides A. Cancer cachexia. Cancer 1979; 43: 2004 2020.

7. Kern KA, Norton JA. Cancer cachexia. J Parent Ent Nutr 1988; 12: 286-298.

8. Dewys WD, Begg C, Lavin PT, et al. Prognostic effect of weight loss prior to chemotherapy in cancer patients. Am J Med 1980; 69: 491-497.

9. Nixon DW, Heymsfield SB, Cohen AE, et al. Proteincalorie undernutrition in hospitalized cancer patients. $\mathrm{Am}$ $J$ Med 1980; 68: 683-690.

10. Feld R, Arriagada R, Ball D, et al. Prognostic factors in non-small cell lung cancer: a consensus report. Lung Cancer 1991; 7: 3-5.

11. Stanley KE. Prognostic factors for survival in patients with inoperable lung cancer. J Natl Cancer Inst 1980; 65: 25-32.

12. Nelson K, Walsch D, Sheehan F. The cancer anorexia cachexia syndrome. J Clin Oncol 1994; 12: 213-225.

13. Fredrix EW, Wouters EF, Soeters PB, et al. Resting energy expenditure in patients with non-small cell lung cancer. Cancer 1991; 68: 1616-1621.

14. Staal AJ, Schols AM, Ten Velde G, Buurman WA, Wouters EF. Analysis of the energy balance in lung cancer patients. Cancer Res 1994; 54: 6430-6433.

15. Staal AJ, Dentener MA, Schols AM, Buurman WA, Wouters EF. Increased resting energy expenditure and weight loss are related to a systemic inflammatory response in lung cancer patients. J Clin Oncol 1995; 13: 2600-2605.

16. Heber D, Chlebowski RT, Ishibashi DE, Richardson B, Block JB. Abnormalities in glucose and protein metabolism in noncachectic lung cancer patients. Cancer Res 1982; 42: 4815-4819.

17. Costa G, Lane WW, Vincent RG, Siebold JA, Aragon $\mathrm{M}$, Bewley PT. Weight loss and cachexia in lung cancer. Nutr Cancer 1981; 2: 98-103.

18. Brennan MF. Supportive care of the cancer patient. In: DeVita VT, Hellman S, Rosenberg SA, eds. Cancer: Principals and Practice of Oncology. Philadelphia, Lippincott. 1985; pp. 1907-1920.

19. Muller JM, Brenner U, Dienst C, Pichlmaier H. Preoperative parenteral feeding in patients with gastrointestinal carcinoma. Lancet 1982; i: 68-71.

20. Clamon G, Feld R, Evans WE, et al. Effect of hyperalimentation on the survival and response to treatment of patients with small cell lung cancer: a randomized trial. Cancer Treat Rep 1985; 69: 167-177.

21. Nixon DW. The value of parenteral nutritional support. Cancer 1986; 58: 1902-1903.

22. Klein S, Simes J, Blackburn G. Total parenteral nutrition and cancer clinical trials. Cancer 1986; 58: 1378-1386.

23. Koretz RL. Parenteral nutrition: is it oncologically logical? J Clin Oncol 1984; 2: 534-538.

24. Kardinal CG, Loprinzi CL, Schaid DJ, et al. A controlled trial of cyproheptadine in cancer patients with anorexia. Cancer 1990; 65: 2657-2662.

25. Kosty MP, Fleishman SB, Herndon JE, et al. Cisplatin, vinblastine and hydrazine sulfate in advanced non-small cell lung cancer: a randomized, placebo-controlled, doubleblind, phase III study of the cancer and leukemia group B. J Clin Oncol 1994: 12: 1113-1120.

26. Chlebowski RT, Bulcavage L, Grosvenor M, et al. Hydrazine sulfate in cancer patients with weight loss: a 
placebo-controlled clinical experience. Cancer 1987; 59: 406-410.

27. Chlebowski RT, Bulcavage L, Grosvenor M, et al. Hydrazine sulfate influence on nutritional status and survival in non-small cell lung cancer. J Clin Oncol 1990; 8: 9-15.

28. Nelson KA, Walsh TD, Sheehan FG, O'Donovan PB, Falk GW. Metoclopramide in anorexia caused by cancer-associated dyspepsia syndrome. J Pall Care 1993: 9: 27-31.

29. Shivshanker K, Bennet RW, Haynie TP. Tumor-associated gastroparesis: correction with metoclopramide. Am J Surg 1983: 145: 221-225.

30. Nelson K, Walsh D, Deeter RP, Sheehan F. A phase II study of delta-9-tetrahydrocannabinol for appetite stimulation in cancer-associated anorexia. J Pall Care 1994: 10: $14-18$.

31. Moertel CG, Schutt AJ, Reitemeier RJ. Corticosteroid therapy of preterminal gastrointestinal cancer. Cancer 1974; 33: 1607-1609.

32. Willox J, Corr J, Shaw J, Richardson M, Calman KC, Drennan M. Prednisolone as an appetite stimulant in patients with cancer. $\operatorname{Br}$ Med $J$ 1984; 288: 27.

33. Bruera E, Roca E, Cedaro L, et al. Action of oral methylprednisolone in terminal cancer patients: a prospective, randomized, double-blind study. Cancer Treat Rep 1985; 69: 751-754.

34. Chlebowski R, Herrold J, Ali I, Oktay E, et al. Influence of nandrolone decanoate on weight loss in advanced nonsmall cell lung cancer. Cancer 1986; 58: 183-186.

35. Nelson KA, Walsh TD. Metoclopramide in anorexia caused by cancer-associated dyspepsia syndrome. J Pall Care 1993: 9: 14-18.

36. Schell HW. The risk of adrenal corticosteroid therapy in far advanced cancer. Am J Med Sci 1966; 252: 641649.

37. Wilson JD. Griffin JE. The use and misuse of androgens. Metab Clin Exp 1980: 29: 1278-1294.

38. Feliu J, Gonzalez-Baron M, Berrocal A, et al. Usefulness of megestrol acetate in cancer cachexia and anorexia. Am J Clin Oncol 1992: 15: 436-440.
39. Loprinzi C, Ellison N, Schaid D, Krook J, et al. Controlled trial of megestrol acetate for the treatment of cancer anorexia and cachexia. Natl Cancer Inst 1990; 82: 1127-1132.

40. Tchekmedyian NS, Hickman M, Siau J, et al. Megestrol acetate in cancer anorexia and weight loss. Cancer 1992; 69: 1268-1274.

41. Schmoll E, Wilke H, Thole R, Preusser P, Wildfang I, Schmoll HJ. Megestrol acetate in cancer cachexia. Semin Oncol 1991; 18 (Suppl.): 32-34.

42. Bruera E, Macmillan K, Kuehn N, Hanson J, MacDonald $\mathrm{RN}$. A controlled trial of megestrol acetate on appetite, caloric intake, nutritional status, and other symptoms in patients with advanced cancer. Cancer 1990; 66: 12791282.

43. Simons JP, Aaronson NT, Vansteenkiste JF, et al. The effects of medroxyprogesterone acetate on appetite, weight and quality of life in advanced stage non-hormonesensitive cancer: a placebo-controlled, multicenter study. J Clin Oncol 1996; 14: 1077-1084.

44. Niiranen A, Kajanti M, Tammilehto L, Mattson K. The clinical effect of medroxyprogesterone (MPA) in elderly patients with lung cancer. Am J Clin Oncol 1990; 13: 113-116.

45. Downer S, Joel S, Allbright A, et al. A double-blind, placebo-controlled trial of medroxyprogesterone acetate (MPA) in cancer cachexia. Br J Cancer 1993; 67: 1102-1105.

46. Pannuti F, Martoni A, Dimarco AR, et al. Prospective randomized clinical trial of two different high dosages of medroxyprogesterone acetate (MPA) in the treatment of metastatic breast cancer. Eur J Cancer 1979; 15: 593-601.

47. Aaronson N, Ahmedzai S, Bergman B, et al. The European Organization for Research and Treatment of Cancer QLQC30: a quality of life instrument for use in international clinical trials in oncology. J Natl Cancer Inst 1993; 85: 365-376.

48. Simons JP, Schols AM, Hoefnagels JM, et al. The effects of medroxyprogesterone acetate (MPA) on energy intake and body composition in patients with advanced cancer. Proc ASCO 1995; 14: 430 (Abstract). 